\title{
Disorders of neural crest derivates in oncoradiological practice
}

\author{
Tamas Papp ${ }^{1 \#}$, Zsuzsanna Ferenczi $^{1 \#}$, Matyas Petro ${ }^{1}$, Zoltan Meszar $^{2}$, Zita Kepes $^{1}$, Ervin Berenyi $^{1}$ \\ ${ }^{1}$ Department of Medical Imaging, ${ }^{2}$ Department of Anatomy, Histology and Embryology, Faculty of Medicine, University of Debrecen, Debrecen, \\ Hungary \\ Contributions: (I) Conception and design: T Papp, Z Meszar, E Berenyi; (II) Administrative support: None; (III) Provision of study materials or \\ patients: None; (IV) Collection and assembly of data: None; (V) Data analysis and interpretation: None; (VI) Manuscript writing: All authors; (VII) \\ Final approval of manuscript: All authors. \\ \#These authors contributed equally to this work. \\ Correspondence to: Dr. Tamas Papp, MD, PhD. Department of Medical Imaging, Faculty of Medicine, University of Debrecen, 1. Egyetem Square, \\ Debrecen 4032, Hungary. Email: papp.tamas@med.unideb.hu.
}

\begin{abstract}
Hundreds of articles discuss the imaging characteristics and molecular background of prominent gastrointestinal (GI) motility disorders and tumors of the peripheral nervous system, but according to our knowledge an article focusing on the classification and developmental background of these heterogeneous diseases is not to be found. Our aim is to give insight on the common features of several diseases and tumors, starting with their common source of origin, the neural crest (NC). The NC is a transient cell population of the embryo, which differentiates into several organs/structures of our body (sympathetic trunk, adrenal medulla). Although the incidence of the individual tumors of NC cells is not high by themselves, the summation of these incidences may be relevant in the daily routine. In the introduction we mention the most prominent developmental routes and molecular pathways of NC cells, which is crucial to understand the pathogenesis and the wide range of involved cell types from the colon to the adrenal gland. We summarized the most important, useful pathological findings and imaging techniques from the $\mathrm{X}$-ray to the positron emission tomography-computed tomography (CT) in order to help the identification of these diseases. This article may help to better understand NC lineage and its unique, diverse role during ontogeny, which may influence the radiologists to change several convictions, or understand better the background and/or connections of a wide range of tumors and syndromes.
\end{abstract}

Keywords: Developmental disorders; embryology; neural crest (NC); oncology; radiology

Submitted Apr 13, 2019. Accepted for publication Aug 28, 2019.

doi: $10.21037 /$ tcr.2019.10.38

View this article at: http://dx.doi.org/10.21037/tcr.2019.10.38

\section{Introduction}

\section{Development of neural crest (NC) cell lines}

The NC originates from the lateral portions of the neural plate and during gastrulation it contributes to the formation of each germ layer (1-3). The NC cells have a very precise timing and signaling program, here we only describe the major molecules which take part in its development (4). To gain mobility they are going through the epithelialmesenchymal transition (EMT), provided by several factors/signaling pathways $(1,5,6)$. The first key element of the EMT is the rhoB protein which is responsible for the delamination of the NC cells from the neural plate. RhoB and Slug protein may be also involved in changing the cytoskeleton in NC cells, promoting migration (5-8). In the second step migrating $\mathrm{NC}$ cells downregulate both $\mathrm{N}$ and E-cadherins to separate from the surface ectoderm and the neuroepithelium and are able to move in the surrounding tissues, they express again $\mathrm{N}$-cadherin as they reach their final destination $(5,6,9)$. The third prominent step of the migration (and EMT) is the secretion of enzymes, which break down the extracellular matrix. Concerning the major routes of NC migration in the body, there are three routes can be distinguished: (I) a cranial route that is responsible 
Table 1 The basic developmental aspects of the pharyngeal arches, including the innervations, skeletal structures and muscles of pharyngeal derivates

\begin{tabular}{llll}
\hline Pharyngeal arches & Bones & Muscles & Cranial nerve \\
\hline I & Mandibula & $\begin{array}{l}\text { Muscles for mastication, tensor tympani, tensor veli } \\
\text { palatini, mylohyoid, anterior belly of digastric }\end{array}$ \\
II & Lesser horn and upper part of the & $\begin{array}{l}\text { Muscles for facial expression, posterior belly of digastric, } \\
\text { hyoid bone, styloid process }\end{array}$ & stylohyoid, stapedius \\
III & Greater horn and lower part of hyoid & Stylopharyngeus, upper part of the pharynx \\
IV-VI & Cartilages of larynx & Pharynx, muscles of the larynx & IX \\
\hline
\end{tabular}

for forming of the placodes and the mesenchymal cells in the pharyngeal arches, (II) a truncal route that gives the melanocytes, sympathetic and paraaortic ganglia, dorsal root ganglia and the parenchyma of the adrenal gland, and (III) a route of the enteric nervous system where NC cells from the anterior (vagal) and a posterior (sacral) regions settle in the gut wall and migrate in a wavelike manner (3).

Cranial route: The mesectoderm forms the majority of the skull and facial skeleton (except the basal part of the occipital bone), the smooth muscle, adipose tissue and the dermis $(3,10)$. Several cell lines such as odontoblasts, C-cells, carotid body type I cells and cephalic meninges partially originate from NC cells. The mesodermal components of the aortic arch also derive from NC cells. NCC's also provide the stroma of the glands of the head and neck and their proper migration also requires $\mathrm{NC}$ cells (1,3). Mutation in the $P a x 3$ gene can cause the absence of NC cells which in turn leads to abnormal placement or even the absence of several glands (parathyroid, thymus) (11-13). The NC cells which originate from the forebrain's region form the frontonasal process and the palate (3). Rhombomeres (segments of the neural tube) are also formed by the NC cells in the territory of the hindbrain. The $1^{\text {st }}-2^{\text {nd }}$ rhombomeres form each derivates of the $1^{\text {st }}$ pharyngeal arch and the frontonasal process, the $2^{\text {nd }}-4^{\text {th }}$ forms the $2^{\text {nd }}$ pharyngeal arch and the $4-6^{\text {th }}$ rhombomeres are responsible for the development of the $3^{\text {rd }}-4^{\text {th }}$ pharyngeal arches and pouches (Table 1) (3). If the NC is excluded from those regions (including rhombomere 6), the thymus, parathyroid glands, and thyroid fail to form (11-13). According to earlier findings, the NCC's of rhombomere 7 are dedicated to form the aortopulmonary septum, it cannot be replaced by another part of the NC, this supports the protomap theory of neural development $(14,15)$.

Truncal and enteric nervous system routes: the truncal route involves three spatially and temporally different migratory pathways: (I) the ventral patbway represents the first populations migrating ventrally between the spinal cord and the somites to form the ganglia of the sympathetic trunk and the paraaortic ganglia as well as the adrenal gland, hence this pathway is often called as sympathoadrenal path $(16,17)$. All the ganglia and other neural elements of the intestines and the lungs originate from NC cells (3). (II) the second wave of the NC cells form the ventrolateral patbway and populate the cells or the sensory ganglia and Schwann cells of the peripheral nervous system (Figure 1) (3). The adrenal medulla initially starts as a condensation of NCC's which, while forming the adrenal medulla lose their neural features almost entirely $(16,17)$. (III) the last wave is the dorsolateral pathway that gives rise to melanocytes.

\section{Developmental-pathophysiological correlation}

During development, several anomalies can cause the abnormal formation of NC cell lines, from chromosomal abnormalities [Di-George syndrome (18)], through gene mutations [MEN2 (19)] to external noxas (20).

There are also several practical facts, which may provide insight on the connection between the above-mentioned molecular background and pathogenesis of NC derivates. The pathogenesis of neuroblastoma (NB) and malignant melanoma (MM) contain similar molecular changes, such as neuroblastoma-Ras (NRAS) expression (proto-oncogene), EMT and production of enzymes, which break down the extracellular matrix $(21,22)$. The NRAS expression is responsible for the continuous mitotic activity of cells, while the EMT transformation and enzyme secretion indicates the malignant potential of tumor cells (23). If MM cells are transplanted into a normal embryonic microenvironment (into an embryo), they lose their malignant potential, and 

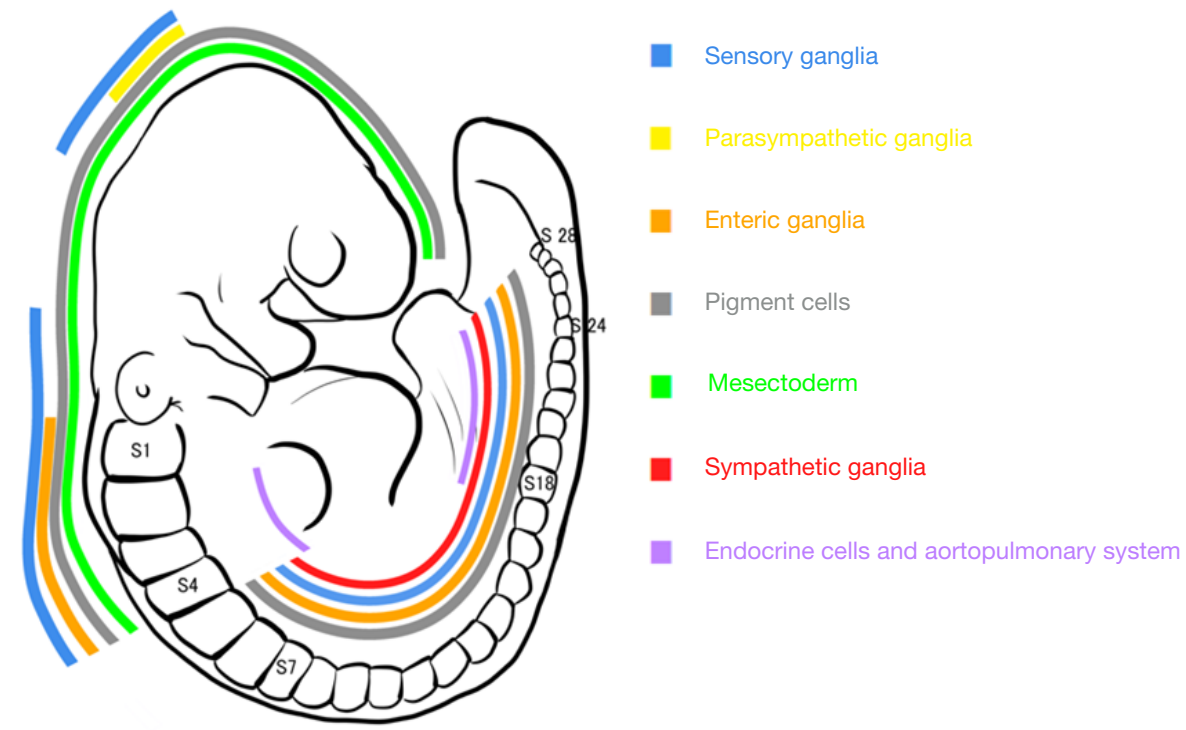

Figure 1 The schematic view of the distribution of neural crest cell derivates. The distribution of NC cell lines in the embryo (S28 embryonal stage), during the folding of embryo the derivates of NC cell lines spread into the whole body of the embryo. All of the sensory, autonomic and enteric ganglia, melanocytes, several endocrine cell lines, and the majority of the facial skeleton forming by NC cells, all cell lines indicating by different colors. NC, neural crest.

start to behave as normal melanocyte precursors. Since the melanocyte cell line is the last wave of the migrating $\mathrm{NC}$ cells, they have to travel through almost all of the tissues, which may contribute to the very high malignant potential of MM.

During the development the Schwann cell precursors are able to differentiate into several cell types, including melanocytes, peripheral neurons, fibroblasts, Schwann cells. This wide cell line variety is important during the regeneration of injuries, since the mature Schwann cells may de-differentiate into precursor-like cells to promote the healing of neighboring structures (such as skin and nerves). This unique feature (de-differentiation) can be the key to understand the presence the diversity of the involved cells types in neurofibromatosis 1 (Schwann cells, fibroblasts, dendritic cells, melanocytes) (21).

\section{Prominent tumors which were originating from mature NC lines}

\section{Prominent tumors of Schwann cell lineage}

Schwannoma and neurofibromatosis 1

Schwannomas are usually solitary, well-circumscribed benign tumors neighboring the peripheral or cranial nerves (24). In the peripheral nervous system or in superficial regions, localized Schwannoma usually on US as a well vascularised lesion (more vascular than neurofibromas) with eccentric location; their average size is a few centimeters (25). Neurofibroma is generally situated in the center of the nerve and they are less vascularised than Schwannomas. Even though both tumors contain Schwann cells, neurofibromas also contain fibroblasts and mastocytes (25). On computed tomography (CT) Schwannoma is hypodense to skeletal muscle with poor to moderate heterogeneous contrast enhancement (24). The $7-8 \%$ of intracranial tumors are Schwannomas surrounding the VIII. cranial nerve (acoustic neurinoma). Intracranially Schwannomas are localized around the cranial nerves except the olfactory and optic nerve (they have glial cells instead of Schwann cells). On CT the tumor is hyperdense in 50\% on unenhanced scan, and causes the bone destruction. In small acoustic neuromas the widening of the internal acoustic canal can be the first imaging finding. On magnetic resonance imaging (MRI), they usually have hyperintense signal on T2-weighted imaging (T2WI) $(26,27)$. On T1weighted imaging (T1WI) they may appear as isointense (Antoni type B or hypocellular tumor) or hyperintense lesions (Antoni type A or hypercellular tumor) with heterogeneous enhancement (26). Neurofibromatosis 
type 1 (NF1) consists of neurofibromas which are built up by Schwann cells, fibroblasts, mast cells and dendritic cells. The diagnosis is based on demonstrating at least 2 of the following 7 clinical criteria: limb hemihypertrophy, pseudoarthrosis, neurofibromas, subcutaneous and plexiform neurofibromas, café au lait sign, gliomas and hamartomas of the iris (Lisch's nodules). The plexiform neurofibromas is pathognomic to NF and affects $10 \%$ of NF1 patients which has malignant potential (28).

\section{Prominent tumors of the ventral pathway (sympathoadrenal cell lineage)}

Paragangliomas are tumors of the sympathetic trunk ganglia and the ganglia of parasympathetic nerves. Based on the widespread presence of vegetative ganglia, the tumors may arise anywhere in the body from the skull (jugulotympanic membrane) to the pelvis. Recent findings indicate that the molecular basis of the development of several paragangliomas contain germline mutations (RET, VHL) $(29,30)$. Note that all neuroendocrine neoplasms express somatostatin receptors, the special ligand is the Indium-111 octreotide (29).

\section{Pheochromocytoma}

It would be more precise if we used 'pheochromocytoma' for the adrenal tumors and 'paraganglioma' for the extraadrenal masses. The CT appearance is largely variable, they can either be heterogenous or homogenous depending on the size and compartments they have, they may show calcification, fatty degradation, cystic and/or solid parts $(31,32)$. Most pheochromocytomas show attenuation higher than $10 \mathrm{HU}$, making the differential diagnosis easier from adenomas (32). In both arterial and venous phases, pheochromocytomas usually take up more contrast medium than adenomas, rapidly $(31,32)$. With MRI, most pheochromocytomas are hyperintense on T2WI (compared to liver) and hypointense on T1WI $(31,32)$. On diffusion-weighted imaging (DWI), the tumors show a heterogeneously high signal intensity (32). The gadolinium enhancement profile of this neoplasm is also heterogeneous without any notable characteristics. Cystic and necrotic parts of the solid tumors do not take up contrast media independently (32). Some of the tumors may contain either septa or walls, these parts show contrast enhancement on MRI images (31). ${ }^{131} \mathrm{I}$ or ${ }^{123} \mathrm{I}$ labeled MIBG scintigraphy is a potential diagnostic tool in nuclear medicine.

\section{Paragangliomas}

Carotid body paraganglioma is a highly vascularised tumor (33), the bifurcation of the common carotid artery is the most common site, the arising tumor can enclose, but does not compress the neighboring great vessels. With US a highly vascularised, solid, visible tumor can be detected adjacent to the carotid sheath. On MRI T2WI the lesion is hyperintense to the vascular nature, the classic "salt and pepper" pattern is obvious (29). Computed tomography angiography (CTA) reveals a hypervascular lesion with large feeding arteries. From a practical approach, the tumors can be divided into three groups (Shambling classification). Group 1 contains tumors that are minimally attached to the vessels and are smaller than $5 \mathrm{~cm}$. Group 2 involves partially enclosed blood vessels and group 3 lesions break through the vessel walls (34). Although it is estimated that less than $10 \%$ of paragangliomas are malignant, in some studies malignancy rates are as high as $50 \%$. It is noteworthy that all carotid body tumors have malignant potential and it is not always possible to predict malignant behavior based only on histological features.

\section{Neuroblastoma}

Radiographic images of NB may reveal a posterior retroperitoneal, mediastinal or neck mass (35). Metastasis may show different manifestations such as hepatomegaly, lucency in the submetaphyseal zones, periosteal reaction, additionally, dural metastases could cause sutural widening (36). On US, NB can contain anechoic areas pertaining to hemorrhage or necrosis. Calcification appears as focal echogenic areas or diffuse hyperechogenecity, the latter caused by fine calcifications (37). US is a useful tool in evaluation of, e.g., the liver for metastases, though it is better to perform CT or MRI (36). On CT, NB's appear as large, lobulated, heterogeneous soft tissue masses with little to no enhancement. Eighty-five percent of abdominal manifestations and $50 \%$ of thoracic manifestations show coarse calcification. Diffuse hepatic metastasis is usually undetectable on CT; lung metastases are rare, they only appear in $3 \%$ of the cases (38). On MRI, NB is usually heterogenous and displays a variable but mostly low enhancement or non-enhancing pattern. T1 hypointensity and T2WI hyperintensity is typical. Unlike calcifications, cystic and hemorrhagic areas within the lesion are commonly visible. On diffusion-weighted images, increased tumor signal can be measured due to restricted diffusion within the tumor matrix (39). In children with paraspinal 
$\mathrm{NB}$, it is better to apply MRI to assess epidural extension. Leptomeningeal dissemination in $10 \%$ of abdominal, $28 \%$ of thoracic and occasionally in cervical NB, dumbbelllike NB's can be seen (35). Bone marrow infiltration is usually diffuse but it may show a nodular pattern, with $\mathrm{T} 1$ hypointensity and $\mathrm{T} 2$ hyperintensity. Bone scan with ${ }^{99} \mathrm{mTc}-$ MDP and ${ }^{123}$ I-MIBG are the most commonly performed examinations. Entirely omitting scintigraphic studies may cause incorrect staging in up to $10 \%$ of cases (35).

\section{Carcinoid}

Carcinoid emerges from the submucosa into the lumen of the gastrointestinal tract or situated in the gut wall $(70-90 \%)$, an uncommon location is the bronchial tree (lung also develops from the foregut) $(40,41)$. The incidence is about $2-5 / 100,000(40,42)$. Carcinoids are usually well circumscribed small lesions (under $2 \mathrm{~cm}$ ) however, some carcinoids can cause an unnatural kink or curvature of the intestinal wall $(40,42)$. In $70 \%$ of the cases calcification in the mesenteric lymph nodes is present, which is an important indirect sign (43). Carcinoids are highly vascularised tumors and generally produce hormones. Small carcinoid $(<1 \mathrm{~cm})$ tumors are usually undetected on CT scans (42), however CT enteroclysis has $100 \%$ sensitivity and $96 \%$ specificity in identifying patients with small bowel neuroendocrine tumors (NETs) (44). Intramural carcinoids may be visible during colonoscopy or gastroscopy. According to limited data, MR enterography and enteroclysis has 86$94 \%$ sensitivity and $95-97 \%$ specificity $(45,46)$. T1-weighted MR images with fat suppression (FS) may be helpful to detect nodules or GI wall thickening with gadolinium enhancement $(40,47)$. Carcinoids express somatostatin receptors, granting the possibility to use ${ }^{111}$ In octreotide for imaging (46). Using ${ }^{18} \mathrm{~F}$-FDG is not widely applied since a low-grade malignancy can be undetectable $(48,49)$.

\section{Medullary thyroid carcinoma}

The calcitonin releasing C-cells take place sporadically in the thyroid gland, their malformation may lead to medullary thyroid carcinoma (MTC) which is around $1 \%$ of all thyroid malignancies (50-52). From the time of diagnosis, the serum calcitonin level is an evident and special marker for follow-up. Echogenicity is variable, calcifications it can be divided into the following groups: microcalcifications (less than $1 \mathrm{~mm}$ ), macrocalcifications (larger than $1 \mathrm{~mm}$ ) or rim calcifications (53). A cystic part inside a nodule is more common in MTC compared with papillary thyroid carcinoma. MTC shows homogeneous echogenicity in $58.7 \%$ of the lesions, which is significantly higher than in the papillary thyroid carcinoma $[30.9 \%$ of the lesions (53)]. CT features of MTC are nonspecific (50). In suspicion of metastasis or invasion CT is preferred, from the skull to the bifurcation of the trachea with 2-mm slices in axial, coronal and sagittal planes, providing the best sensitivity (54). In case of metastases to the CNS and abdomen, MRI is the best choice (54). A head and neck protocol covering the same anatomical territories with $\mathrm{T} 1$, T2 FS images, followed by post-contrast T1 images has the best specificity in finding metastases $(54,55)$.

\section{Prominent tumors of melanocytic lineage}

\section{Melanoma}

CT, US and chest radiography has very poor efficiency (around $0.1 \%$ ) to screen patients for early stage melanoma, especially in asymptomatic patients (56). The sensitivity of US is $39-79 \%$ and specificity is almost $100 \%$ (57). $\mathrm{PET} / \mathrm{CT}$ is the best imaging approach in finding metastasis (97\% sensitivity) $(57,58)$. MRI can show characteristic signal features such as T1 hyperintensity and T2 hypointensity with hypointensity on the short-tau inversion recovery (STIR) sequence since melanin contains metal ions in paramagnetic compounds $(59,60)$. The amelanotic type shows the opposite signal intensity on MRI due to the absence of melanin, furthermore, hemorrhagic components (found in up to $40 \%$ of cases) may also alter the signal intensity. The CNS and its adnexes contain metastases in $7 \%$ of the cases according to dissection reports (60). CT, MRI and ultrasound are the most common radiological imaging tools used in scanning for metastases; however the slice thickness or resolution has to be under $2 \mathrm{~mm}$ (56). In scanning for intrathoracic metastasis, CT is the first choice. On CT metastases are usually iso- or hypodense; enhancement is typical in abdominal lesions, the specificity is $87 \%(57,60)$

\section{Abnormal migration of NC cells}

\section{Dysganglionosis group}

The dysganglionosis group contains gastrointestinal disorders based on the abnormal migration of $\mathrm{NC}$ cells that can involve all segments of the gastrointestinal tract from the esophagus to the rectum, however the most commonly involved site is the colon (61). In hypo-, or aganglionosis the following abnormalities can be seen: narrowing of the lumen where the ganglion cells are missing and prestenotic 
dilatation of the lumen usually with air-fluid level, achalasia may develop which can be divided into primary and secondary achalasia.

Hirschsprung disease, also coined congenital megacolon, has an incidence of 1 in 5,000 live births (62). The most prominent symptoms are delayed meconium defecation, abdominal distension, vomiting and enterocolitis, however, in many cases the patient is asymptomatic until adolescence (63). On plain radiography a transition zone can be seen between the gas-filled colon and a nondilated proximal colon. The first imaging procedure may be contrast enema with barium which reveals not only the transition zone, but also the irregular colonic contractions, irregular mucosa (suggesting enterocolitis), and an abnormal rectosigmoid index (64). In adults, CT and double-contrast enema reveals a markedly dilated proximal colonic segment with a transition zone and a narrowed distal colonic segment can be detected in conjunction with chronic refractory constipation.

\section{Multiple lineage tumor syndromes}

\section{Multiple endocrine neoplasia 2}

MEN2 is a hereditary disease in which the RET gene, which has a principal role during the development, migration of NC cells, is subject to mutation. MEN2 includes pheochromocytoma, medullary thyroid carcinoma, acoustic neurinoma, parathyroid hyperplasia. Additionally, the connection between MEN2 and Hirschsprung disease is not well understood, but overlapping between these abnormalities is evident according to statistical analysis (65).

\section{Conclusions}

In this article we attempted to highlight a connection between the general developmental processes of NC cells and the daily radiological practice. Routinely the radiologist is not responsible in establishing a diagnosis in the majority of the discussed tumors. It is worth noting that several tumors can be a part (or first element) of the abovementioned syndromes/diseases. Numerous articles contain poorly-defined practical information about the coincidence of at least two tumors/disorders of NC cell derivates, without firm conclusion. To our current understanding the scientific background is not well understood regarding the coincidence of the diseases mentioned previously, but indicates that we have to consider these diseases as a homogenous group from a developmental aspect.

\section{Acknowledgments}

Funding: This work was supported by: the Hungarian National Brain Research Program (KTIA_NAP_13-12013-0001), National Brain Research Program 2 (20171.2.1-NKP-2017-00002) and OTKA: NKFI-108467.

\section{Footnote}

Conflicts of Interest: All authors have completed the ICMJE uniform disclosure form (available at http://dx.doi. org/10.21037/tcr.2019.10.38). The authors have no conflicts of interest to declare.

Ethical Statement: The authors are accountable for all aspects of the work in ensuring that questions related to the accuracy or integrity of any part of the work are appropriately investigated and resolved.

Open Access Statement: This is an Open Access article distributed in accordance with the Creative Commons Attribution-NonCommercial-NoDerivs 4.0 International License (CC BY-NC-ND 4.0), which permits the noncommercial replication and distribution of the article with the strict proviso that no changes or edits are made and the original work is properly cited (including links to both the formal publication through the relevant DOI and the license). See: https://creativecommons.org/licenses/by-nc-nd/4.0/.

\section{References}

1. Bronner ME. Formation and migration of neural crest cells in the vertebrate embryo. Histochem Cell Biol 2012;138:179-86.

2. Gilbert SF. Developmental Biology. 6th edition. Sunderland (MA): Sinauer Associates; 2000.

3. Ruhrberg C, Schwarz Q. In the beginning: Generating neural crest cell diversity. Cell Adh Migr 2010;4:622-30.

4. Le Douarin NM, Creuzet S, Couly G, et al. Neural crest cell plasticity and its limits. Development 2004;131:4637-50.

5. Hay ED. The mesenchymal cell, its role in the embryo and the remarkable signaling mechanisms that create it. Dev Dyn 2005;233:706-20.

6. Theveneau E, Mayor R. Neural crest delamination and migration: From epithelium-to-mesenchyme transition to collective cell migration. Dev Biol 2012;366:34-54.

7. Berndt JD, Clay MR, Langenberg T, et al. Rho-kinase and 
myosin II affect dynamic neural crest cell behaviors during epithelial to mesenchymal transition in vivo. Dev Biol 2008;324:236-44.

8. Clay MR, Halloran MC. Control of neural crest cell behavior and migration. Cell Adh Migr 2010;4:586-94.

9. Langenberg T, Kahana A, Wszalek JA, et al. The eye organizes neural crest cell migration. Dev Dyn 2008;237:1645-52.

10. Graham A, Begbie J, McGonnell I. Significance of the cranial neural crest. Dev Dyn 2004;229:5-13.

11. Maeda K, Asai R, Maruyama K, et al. Postotic and preotic cranial neural crest cells differently contribute to thyroid development. Dev Biol 2016;409:72-83.

12. Bockman DE, Kirby ML. Dependence of thymus development on derivatives of the neural crest. Science 1984;223:498-500.

13. Conway SJ, Henderson DJ, Copp AJ. Pax3 is required for cardiac neural crest migration in the mouse: Evidence from the splotch $(\mathrm{Sp} 2 \mathrm{H})$ mutant. Development 1997;124:505-14.

14. Rakic P. Specification of cerebral cortical areas. Science 1988;241:170-76.

15. Wilson DI, Burn J, Scambler J, et al. DiGeorge syndrome: part of CATCH 22. J Med Genet 1993;30:852-6.

16. Huber K. The sympathoadrenal cell lineage: Specification, diversification, and new perspectives. Dev Biol 2006;298:335-43.

17. Kameda Y. Signaling molecules and transcription factors involved in the development of the sympathetic nervous system, with special emphasis on the superior cervical ganglion. Cell Tissue Res 2014;357:527-48.

18. Kochilas L, Merscher-Gomez S, Lu MM, et al. The role of neural crest during cardiac development in a mouse model of DiGeorge syndrome. Dev Biol 2002;251:157-66.

19. Hansford JR, Mulligan LM. Multiple endocrine neoplasia type 2 and RET: from neoplasia to neurogenesis. J Med Genet 2000;37:817-27.

20. Smith SM, Garic A, Flentke GR, et al. Neural crest development in fetal alcohol syndrome. Birth Defects Res C Embryo Today 2014;102:210-20.

21. Nozato M, Kaneko S, Nakagawara A, et al. Epithelialmesenchymal transition-related gene expression as a new prognostic marker for neuroblastoma. Int J Oncol 2013;42:134-40.

22. Jiang M, Stanke J, Lahti JM. The connections between neural crest development and neuroblastoma. Curr Top Dev Biol 2011;94:77-127.

23. Liu Y, Sheikh MS. Melanoma: molecular pathogenesis and therapeutic management. Mol Cell Pharmacol 2014;6:228.

24. Silver AJ, Mawad ME, Hilal SK, et al. Computed tomography of the carotid space and related cervical spaces. Part II: Neurogenic tumors. Radiology. 1984;150:729-35.

25. Ryu JA, Lee SH, Cha EY, et al. Sonographic differentiation between schwannomas and neurofibromas in the musculoskeletal system. J Ultrasound Med 2015;34:2253-60.

26. Anil G, Tan TY. Imaging characteristics of schwannoma of the cervical sympathetic chain: a review of 12 cases. AJNR Am J Neuroradiol 2010;31:1408-12.

27. Baba Y, Ohkubo K, Seino N, et al. MR imaging appearances of schwannoma: correlation with pathological findings. Nihon Igaku Hoshasen Gakkai Zasshi 1997;57:499-504.

28. Ferner RE, O'Doherty MJ. Neurofibroma and schwannoma. Curr Opin Neurol 2002;15:679-84.

29. Wieneke JA, Smith A. Paraganglioma: carotid body tumor. Head Neck Pathol Pathol 2009;3:303-06.

30. Favier J, Amar L, Gimenez-Roqueplo AP. Paraganglioma and phaeochromocytoma: from genetics to personalized medicine. Nat Rev Endocrinol 2015;11:101-11.

31. Shen Y, Zhong Y, Wang H, et al. MR imaging features of benign retroperitoneal extra-adrenal paragangliomas, Sci Rep 2017;7:4517.

32. Blake MA, Kalra MK, Maher MM, et al. Pheochromocytoma: an imaging chameleon. Radiographics 2004;24:S87-99.

33. Ma D, Liu M, Yang H, et al. Diagnosis and surgical treatment of carotid body tumor: A report of 18 cases. J Cardiovasc Dis Res 2010;1:122-24.

34. Shamblin WR, ReMine WH, Sheps SG, et al. Carotid body tumor (chemodectoma). Clinicopathologic analysis of ninety cases. Am J Surg 1971;122:732-39.

35. Lonergan GJ, Schwab CM, Suarez ES, et al. Neuroblastoma, ganglioneuroblastoma, and ganglioneuroma: radiologic-pathologic correlation. Radiographics 2002;22:911-34.

36. Hiorns MP, Owens CM. Radiology of neuroblastoma in children. Eur Radiol 2001;11:2071-81.

37. Meyer JS, Harty MP, Khademian Z. Imaging of neuroblastoma and Wilms' tumor. Magn Reson Imaging Clin N Am 2002;10:275-302.

38. Papaioannou G, McHugh K. Neuroblastoma in childhood: review and radiological findings. Cancer Imaging 2005;5:116-27.

39. Uhl M, Altehoefer C, Kontny U, et al. MRI-diffusion imaging of neuroblastomas: first results and correlation to 
histology. Eur Radiol 2002;12:2335-38.

40. Ganeshan D, Bhosale P, Yang T, et al. Imaging features of carcinoid tumors of the gastrointestinal tract. AJR Am J Roentgenol 2013;201:773-86.

41. Levy AD, Sobin LH. Gastrointestinal carcinoids: imaging features with clinicopathologic comparison. Radiographics 2007;27:237-57.

42. Taal BG, Visser O. Epidemiology of neuroendocrine tumours. Neuroendocrinology 2004;80:3-7.

43. Pantongrag-Brown L, Buetow PC, Carr NJ, et al. Calcification and fibrosis in mesenteric carcinoid tumor: CT findings and pathologic correlation. AJR Am J Roentgenol 1995;164:387-91.

44. Kamaoui I, De-Luca V, Ficarelli S, et al. Value of CT enteroclysis in suspected small-bowel carcinoid tumors. AJR Am J Roentgenol 2010;194:629-33.

45. Masselli G, Polettini E, Casciani E, et al. Small-bowel neoplasms: prospective evaluation of MR enteroclysis. Radiology 2009;251:743-50.

46. Van Weyenberg SJ, Meijerink MR, Jacobs MA, et al. MR enteroclysis in the diagnosis of small-bowel neoplasms. Radiology 2010;254:765-73.

47. Bader TR, Semelka RC, Chiu VC, et al. MRI of carcinoid tumors: spectrum of appearances in the gastrointestinal tract and liver. J Magn Reson Imaging 2001;14:261-69.

48. Adams S, Baum R, Rink T, et al. Limited value of fluorine-18 fluorodeoxyglucose positron emission tomography for the imaging of neuroendocrine tumours. Eur J Nucl Med 1998;25:79-83.

49. Erasmus JJ, McAdams HP, Patz EF Jr, et al. Evaluation of primary pulmonary carcinoid tumors using FDG PET. AJR Am J Roentgenol 1998;170:1369-73.

50. Ganeshan D, Paulson E, Duran C, et al. Current update on medullary thyroid carcinoma AJR Am J Roentgenol 2013;201:W867-76.

51. Hundahl SA, Fleming ID, Fremgen AM, et al. A national cancer data base report on 53,856 cases of thyroid carcinoma treated in the U.S., 1985-1995. Cancer 1998;83:2638-48

52. Toledo SPA, Lourenço DM Jr, Santos MA, et al. Hypercalcitoninemia is not pathognomonic of medullary thyroid carcinoma. Clinics 2009;64:699-706.

53. Lee S, Shin JH, Han B, et al. Medullary thyroid carcinoma: comparison with papillary thyroid carcinoma and application of current sonographic criteria. AJR Am J Roentgenol 2010;194:1090-94.

54. Giraudet AL, Vanel D, Leboulleux S, et al. Imaging medullary thyroid carcinoma with persistent elevated calcitonin levels. J Clin Endocrinol Metab 2007;92:4185-90.

55. Hoang JK, Branstetter BF 4th, Gafton AR, et al. Imaging of thyroid carcinoma with CT and MRI: approaches to common scenarios. Cancer Imaging 2013;13:128-39.

56. King DM. Imaging of metastatic melanoma. Cancer Imaging 2006;6:204-08.

57. Mohr P, Eggermont AMM, Hauschild A, et al. Staging of cutaneous melanoma. Ann Oncol 2009;20:vi14-21.

58. Reinhardt MJ, Joe AY, Jaeger U, et al. Diagnostic performances of whole-body dual modality 18F-FDG PET/CT imaging for $\mathrm{N}$ - and M-staging of malignant melanoma: experience with 250 consecutive patients. J Clin Oncol 2006;24:1178-87.

59. Premkumar A, Marincola F, Taubenberger J, et al. Metastatic melanoma: correlation of MRI characteristics and histopathology. J Magn Reson Imaging 1996;6:190-94.

60. Wong VK, Lubner MG, Menias CO, et al. Clinical and imaging features of noncutaneous melanoma. AJR Am J Roentgenol 2017;208:942-59.

61. Katz PO, Castell DO. Review: esophageal motility disorders. Am J Med Sci 1985;290:61-9.

62. Alehossein M, Roohi A, Pourgholami M, et al. Diagnostic accuracy of radiologic scoring system for evaluation of suspicious hirschsprung disease in children. Iran J Radiol 2015;12:e12451.

63. Kliegman RM, Behrman RE, Jenson HB, et al. Nelson Textbook of Pediatrics. 18th ed. Philadelphia: Saunders Company; 2007.

64. de Lorijn F, Kremer LC, Reitsma JB, et al. Diagnostic tests in Hirschsprung disease: a systematic review. J Pediatr Gastroenterol Nutr 2006;42:496-505.

65. Moore SW, Zaahl M. The Hirschsprung's-multiple endocrine neoplasia connection. Clinics 2012;67:63-7.
Cite this article as: Papp T, Ferenczi Z, Petro M, Meszar Z, Kepes Z, Berenyi E. Disorders of neural crest derivates in oncoradiological practice. Transl Cancer Res 2019;8(8):2916-2923. doi: $10.21037 /$ tcr.2019.10.38 